\title{
Surface markers of liver cancer stem cells and innovative targeted-therapy strategies for HCC (Review)
}

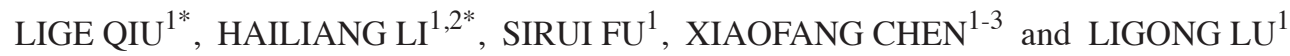 \\ ${ }^{1}$ Department of Intervention, Zhuhai People's Hospital, Zhuhai Hospital Affiliated with Jinan University, \\ Zhuhai, Guangdong 519000; ${ }^{2}$ Department of Otolaryngology Head and Neck Surgery, Zhujiang Hospital, \\ Southern Medical University, Guangzhou, Guangdong 510280; ${ }^{3}$ Stem Cell and Regenerative Medicine Laboratory, \\ Beijing Institute of Transfusion Medicine, Beijing 100850, P.R. China
}

Received March 6, 2017; Accepted November 2, 2017

DOI: $10.3892 / \mathrm{ol} .2017 .7568$

\begin{abstract}
Liver cancer stem cells (LCSCs) have important roles in the occurrence, development, recurrence, therapy resistance and metastasis of hepatocellular carcinoma (HCC). Therefore, intensive studies are undergoing to identify the mechanisms by which LCSCs contribute to HCC invasion and metastasis, and to design more efficient treatments for this disease. With continuous efforts in LCSC research over the years, therapies targeting LCSCs are thought to have great potential for the clinical treatment and prognosis of liver cancer. Novel LCSC surface markers are continuously discovered and several have been used in targeted therapies to reduce HCC recurrence, metastasis, and drug resistance following tumor resection. The present review describes the surface markers characterizing LCSCs and the recent progress in therapies targeting these markers, including antibodies and polypeptides.
\end{abstract}

\section{Contents}

1. Introduction

2. LCSCs and their origin

3. LCSCs and their characteristics in HCC

4. Currently known LCSC surface markers

5. LCSC surface markers and targeted therapies

6. Other LCSC targets and their new applications in tumor therapy

7. Conclusions and perspectives

Correspondence to: Dr Ligong Lu, Department of Intervention, Zhuhai People's Hospital, Zhuhai Hospital Affiliated with Jinan University, 79 Kangning Street, Zhuhai, Guangdong 519000, P.R. China

E-mail: 1lg0902@sina.com

${ }^{*}$ Contributed equally

Key words: liver cancer, stem cells, biomarkers, molecular targeting, cancer therapy

\section{Introduction}

Hepatocellular carcinoma (HCC) is the seventh most common cancer worldwide. Traditional therapy strategies currently available for HCC include surgical procedures, radioactive particle implantation, radiofrequency ablation, hepatic artery chemoembolization (TACE), and chemotherapeutics. Recent studies have indicated that these therapy strategies are still not fully efficient and have multiple drawbacks, including post-treatment relapse, chemotherapy drug resistance and metastasis (1-5). Thus, discovering approaches to avoid recurrence and metastasis of liver cancer and to provide novel therapeutic strategies is of outmost importance in HCC. With the continuous progress in cancer stem cell (CSC) research, many specific studies overexpressed on the surface of CSCs have been discovered. These receptors are significantly associated with growth and proliferation of tumor cells. To date, scientists have isolated CSCs in various solid tumors, including liver, breast, lung and brain cancer. Liver cancer stem cells (LCSCs) represent a small fraction of cells in HCC cancer tissues that possess the abilities of self-renewal, multi-directional differentiation and indefinite proliferation, as well as high tumorigenic ability (6-10). As specific markers of CSCs, the CSC-specific overexpressed receptors may offer a new research direction as therapeutic targets for the diagnosis and treatment of tumors. Currently, potential clinical treatments targeting CSC include: Blocking signal transduction pathways in CSCs; inducing differentiation of CSCs; changing the microenvironment and inhibiting telomerase activity in CSCs; specific gene therapy targeting CSCs; specific compounds or drugs targeting CSCs; and ligands targeting CSCs. In conclusion, the CSC theory may provide an explanation as to the refractory nature of liver cancer and may provide useful insights for scientists to design novel therapies for HCC.

\section{LCSCs and their origin}

The liver has both exocrine and endocrine functions. It is estimated that the normal liver can completely self-renew within $\sim 1$ year (11), exhibiting a strong regeneration capacity, which is also an important feature of stem cells. While there is a large amount of endogenous stem cells in the liver, the duration of 
their proliferative potential is short. These cells are commonly derived from undifferentiated liver oval cells, also known as hepatic precursor cells (HPC), and are located in the terminal bile canaliculi and beside the interlobular bile duct (12-14). Oval cells have both the ability to differentiate into hepatocytes and bile duct cells, which, in human HCC, display the properties of stem cells (15). Additionally, the majority of hepatic stem cell surface markers are the same as hepatic oval cell markers (OV)6, OV1, cytokeratin 7 (CK7) and CK19, $\alpha$-fetoprotein (AFP), KIT proto-oncogene receptor tyrosine kinase (c-kit), and Thy-1 cell surface antigen (Thy-1). OV6 expression is a specific phenotype of oval cells that was originally identified in the livers of tumor-bearing rats, and is recognized as a surface marker of human liver progenitor cells (16). Yang et al (17) reported that overexpression of OV6 enhances the invasiveness and metastasis potential of $\mathrm{HCC}$ stem cells, and that increased numbers of $\mathrm{OV}^{+} \mathrm{CSCs}$ in patients with liver cancer indicate worst clinicopathological features and poorer prognosis. In addition, Yang et al (17) demonstrated that the stromal cell derived factor (SDF)-1/C-X-C motif chemokine receptor (CXCR) 4 signaling pathway is significantly associated with the migration ability of $\mathrm{OV}^{+} \mathrm{HCC}$ cells, suggesting that $\mathrm{OV}^{+}$stem cells have an important role in HCC metastasis. By contrast, exogenous liver stem cells, which are derived from bone marrow or peripheral blood stem cells, are usually fewer in number, but exhibit a longer duration of proliferative potential (18).

Gene mutations, with the exception of mutations affecting self-renewal capacity, are important events occurring in the early stages of cancer. Previous studies have reported that CSCs originate from normal stem/progenitor cells and exhibit certain self-renewal ability (19). However, whether this hypothesis applies to HCC is unknown. Previous studies have demonstrated that there is indeed a small subset of cells in HCC that display the characteristics of CSCs. Side population (SP) cell sorting is widely used for the isolation and identification of CSCs from other types of tumors. The subsets of SP cells are identified by the ability of the ATP binding cassette transporter to export the DNA dye, Hoechst 33342. In the Huh7 and PLC/PRF/5 HCC cell lines, $\sim 0.25-2.0 \%$ of the cells display an SP phenotype (20).

LCSCs can self-replicate, differentiate, and present strong drug resistance. Liu et al (21) (Fig. 1) have hypothesized that CSCs are not derived from a specific source of cells in hepatitis-B (HBV)-associated HCC and may be derived either from hematopoietic stem cells (HSC) or from mesenchymal stem cells (MSC). The specific surface marker for HSCs is CD133, while the specific surface markers for MSCs are CD90 and CD44. Both HSCs and MSCs can differentiate into pluripotent stem cells (PSCs). PSCs can then differentiate into liver precursor cells/oval cells that express OV6 and epithelial cell adhesion molecule (EpCAM). PSCs and liver precursor cells can be induced into CSCs by the mechanism of 'maturation arrest', thus leading to the occurrence of liver cancer.

There are several theories regarding the origin of $\mathrm{HCC}$ cells. One theory proposes that they are derived from dedifferentiated mature liver cells. Gournay et al (22) have confirmed that dedifferentiation of mature liver cells occurs during the formation of $\mathrm{HCC}$ in mice, suggesting that proliferative liver cells may be one of the sources of LCSCs. Other scholars argue that $\mathrm{HCC}$ cells are derived from the abnormal differentiation of liver stem cells by 'blocked maturation'. For example, Sell et al (23) used chemical carcinogens and oncogenes to intervene in the differentiation of liver oval cells and to transform them into HCC pre-cancer cells. Dumble et al (24) subcutaneously inoculated oval cells into nude mice and reported the development of tumors similar to HCC. Results from the detection of surface markers demonstrated that the newly developed tumors were derived from differentiated oval cells, suggesting that oval cells may be involved in the occurrence of HCC (24). HCC tumors have also been demonstrated to include intermediate cells between HPC and mature hepatocytes. An increasing number of studies has demonstrated that LCSCs can originate from the 'blocked maturation' LSCs (25-27), because most HCCs consist of mixtures of mature cells and cells with a phenotype similar to HPCs. Immunophenotyping analysis of HCCs has further indicated that $28-50 \%$ of HCC cells express HPC surface markers, such as CK7 and CK19 (28). These tumors also include intermediate cells between HPC and mature liver cells. Furthermore, Yeh et al (29) reported that the expression levels of CD133 were negatively correlated with the expression levels of HBV surface antigen (HBsAg) in $\mathrm{HBV}$-associated liver cancer tissue samples, indicating that LCSCs more likely originate from blocked liver stem cells, rather than differentiated liver cells post-infection. Therefore, various LCSC markers can be detected in HBV-associated clinical samples of HCC. There is also evidence suggesting that LCSCs may be derived from bone marrow stem cells (30) and SP cells $(20,31)$.

Cancers exhibit immense tumor heterogeneity. If cancers originate from few CSCs and these stem cells offer various characteristics to the tissue, then the importance of cell abnormal differentiation ability needs to be redefined to better explain the heterogeneity of tumors. Dynamic analysis of the expression levels of LCSC markers can help clarify the changes of biological characteristics of LCSCs during hepatocarcinogenesis and explain the clinical significance of the changes in marker expression levels.

\section{LCSCs and their characteristics in HCC}

Drug resistance is associated with the recurrence and metastasis of cancer (32). CSCs resist chemotherapy-induced cell death through various mechanisms, including intrinsic and external mechanisms. The intrinsic mechanism consists of the self-renewal ability of CSCs, the enhancement of DNA damage repair pathways, the high expression of drug efflux-related proteins, the overactivation of growth pathways and other stem-related pathways. The external mechanism refers to the influence of tumor microenvironment factors on CSC resistance, including hypoxia stimulation, epithelial-mesenchymal transition (EMT) signals, and angiogenesis abnormalities (33). In HCC, SP cells or LCSCs expressing other molecular markers (including EpCAM, CD133, CD90, CD44 and CD13) exhibited resistance to radiotherapy and chemotherapy in vitro and in vivo. The mechanisms involved include increased expression of drug efflux-related proteins (31,34-36), activation of anti-apoptotic pathways (37-39), activation of stem cell-related pathways, and increased resistance and maintenance of a certain number of LCSCs $(16,40)$. MicroRNAs (miRNAs) 


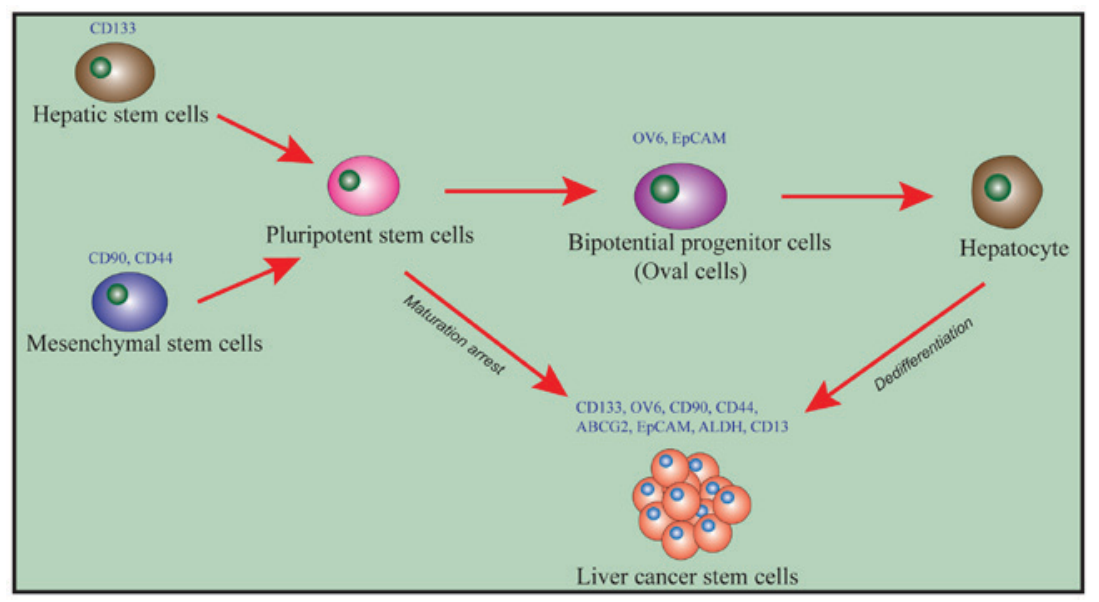

Figure 1. Possible cellular origins and markers of LCSCs. HCC may arise from cells at various stages of differentiation in the hepatic stem cell lineage: Mature liver cells; liver progenitor cells or oval cells as bipotential stem cells; and bone marrow stem cells, including hematopoietic and mesenchymal stem cells as multipotent liver stem cells. HCC could originate from stem cells either due to 'maturation arrest' or to 'dedifferentiation of mature cells'. LCSCs, liver cancer stem cells; HCC, hepatocellular carcinoma; CD133, prominin-1; OV, oval cell marker antibody; EpCAM, epithelial cell adhesion molecule; ABCG2, ATP binding cassette subfamily G member; ALDH, aldehyde dehydrogenase.

participate in the maintenance of the CSC phenotype by regulating the expression of oncogenes and stem cell-related genes $(41,42)$. The half-life of mature tumor cells in the circulation is very short and most of them die from natural apoptosis, with a relatively small effect on tumor invasion and metastasis. A previous study revealed that the viability, distant metastasis, and homing ability of LCSCs in the circulatory system were significantly higher than that of other tumor cells (43). This may be explained by the EMT status of LCSCs, which enables them to serve a leading role in the metastasis and invasion of HCC and to become the source of HCC recurrence (43). Theoretically, tumor recurrence may be effectively prevented if a method to eliminate CSCs could be developed, making CSCs a desirable diagnosis and treatment target for resistant tumors, including HCC (44). This would be especially true for cases with poor therapeutic effect by traditional methods. LCSC-targeted therapy is thus hypothesized to achieve excellent antitumor effects and to reduce the side effects of chemotherapy, providing novel more efficient strategies for the treatment of cancer.

\section{Currently known LCSC surface markers}

With the identification of specific surface markers, LCSCs can be successfully separated and enriched through screening for these markers by fluorescence-activated and magnetic-activated cell sorting methods (45). If LCSC-specific molecular markers are targeted and blocked, the number of LCSCs may be reduced, potentially resulting to inhibited tumor growth and recurrence.

To date, the commonly-reported LCSC surface markers are EpCAM (also known as CD326), CD133, CD90 (also known as Thy-1), CD44, and CD13 (40,46-49). In addition, other surface markers have also been demonstrated to be involved, including OV6, K19, c-kit (also known as CD117), ATP binding cassette subfamily G member 2 (ABCG2), and aldehyde dehydrogenase (ALDH).

Most of these markers normally exist on the surface of HSCs. Cells expressing these markers have similar stem cell properties, therefore these markers are hypothesized to be used as molecular therapeutic targets to eliminate LCSCs and to overcome cancer recurrence. Although certain other surface markers have been reported on cancer stem cells, they are not specific to LCSCs (50).

\section{LCSC surface markers and targeted therapies}

Prominin-1 (CD133). CD133 is one of the most studied stem cell surface markers in recent years. In solid tumors, CD133 was first discovered and isolated in brain tumors; Singh et al (51) successfully isolated CD133+ tumor cells from glioblastoma and demonstrated that $\mathrm{CD}_{133^{+}}$glioblastoma tumor cells can form neurosphere-like clones, with a strong self-renewal capacity, differentiation potential and tumorigenicity in vivo. The tumor cells and subtypes of tumors formed in mice were the same as those obtained by orthotopic grafts, but could also be passaged consecutively; therefore, $\mathrm{CD} 133^{+}$cells were identified as tumor stem cells. Furthermore, CD133 ${ }^{+}$cells have an important role in multiple other solid tumors, including gastric (52), liver (53-55) and colon cancer (56,57). CD133 is a transmembrane glycoprotein with a unique structure of five transmembrane domains and two large extracellular glycosylation chains, expressed in both hematopoietic and neural stem cells (58). In several studies of HCC, the HSC surface marker CD133 was used to isolate LCSCs $(47,54)$. CD133 is expressed on the surface of stem cells in many solid tumors, including liver, colon, brain, lung and prostate cancer, and in B16 melanoma (59). In human HCC cell lines, $~ 0-65 \%$ of cells are $\mathrm{CD}_{133}{ }^{+}$cells. CD133 is considered one of the main LCSC markers, with self-renewal, multi-lineage differentiation and chemoresistance abilities (37). Methionine adenosyltransferase (MAT) is the only enzyme that can catalyze the biosynthesis of S-adenosylmethionine (SAMe), which is the principal biological methyl donor in cells. SAMe can regulate hepatocyte growth and apoptosis. Exogenous SAMe inhibits the growth of hepatoma cells and prevents HCC development. Similar results were observed in a MAT deficiency-induced HCC mouse model (60). Xenografts of CD133+ cells in nude mice formed 
tumors, while CD133 cells did not (61); Yang et al (48) also reported that $\mathrm{CD} 133^{+}$liver cancer cells exhibited higher tumorigenic and proliferative abilities, properties that are similar to the features of HPCs (47). CD133 knockout may reduce the tumorigenicity and change the cell cycle distribution in these cells. Additionally, HCC patients with high CD133 expression in their tumors have poor prognosis and increased recurrence, indicating that $\mathrm{CD} 133$ expression may be associated with the prognosis of liver cancer $(47,54,62-64)$. A previous study has demonstrated that the migration of $\mathrm{CD}_{133^{+}}$and $\mathrm{CD} 133^{-}$cells was not significantly different, and that the CD133 expression pattern was inconsistent with the clinical manifestations (65). A recent study reported that $\mathrm{CD} 133^{+} \mathrm{LCSC}$ s were resistant to interferon-induced autophagy (66). Therefore, the identification of targeted molecular markers is of great significance.

Monoclonal antibodies are commonly used as ligands in CD133-targeted therapy. These antibodies can carry various drugs or toxins to the target in order to enhance the immune response of the human body towards the disease. Such methods have several advantages that are absent in traditional anticancer drugs, namely, relatively high target specificity, low molecular weight, less side effects, and better patient compliance. Currently reported antibodies against CD133 are AC133, 293C3 and AC141, among which AC141 and 293C3 are antibodies targeting CD133/2. CD133/2 is a variant of the CD133 antigen, which is predominantly expressed in the fetal liver and kidney, but not in the adult pancreas and placenta tissues. Prasad et al (67) prepared a compound antibody from CD133 and CD3 antibodies. This compound could specifically identify glioma stem cells and recruit $\mathrm{T}$ cells to kill these stem cells, demonstrating an excellent targeted therapeutic effect. Smith et al (68) combined a mouse anti-human CD133 antibody with the anti-microtubule cytotoxic drug monomethyl auristatin $\mathrm{E}$, and confirmed that this complex inhibited the growth of $\mathrm{CD}_{133^{+}}$LCSC-like cells in vivo and in vitro. Lang et al (69) prepared a ${ }^{131}$ I-CD133 monoclonal antibody $(\mathrm{mAb})$ with high stability and specificity in vitro. Additionally, in vivo experiments demonstrated that the ${ }^{131} \mathrm{I}-\mathrm{CD} 133 \mathrm{mAb}$ had a high selectivity, and the binding rates with $\mathrm{CD} 133^{+}$colon adenocarcinoma CSCs and CD133 cells were 70.01 \pm 6.02 and $2.73 \pm 0.26 \%$, respectively (69). Imaging of the transplanted tumor mice demonstrated that most of the ${ }^{131} \mathrm{I}-\mathrm{CD} 133 \mathrm{mAb}$ was deposited in the $\mathrm{CD} 133^{+}$-transplanted tumor sites in the mice, while this was not observed in CD133 mice. The ${ }^{131} \mathrm{I}-\mathrm{CD} 133 \mathrm{mAb}$ may be therefore applied with high selectivity and high stability in the clinical diagnosis of LCSCs, as well as for immune imaging and radiation therapy of LCSCs, and clinical trials are currently ongoing.

In the field of CD133-targeted polypeptides, Sun et al (70) successfully identified a short peptide LQNAPRS (LS-7) which can highly bind to mouse CD133, by using phage display technology. Wang et al (71) prepared a DSPEPEG micelle system loaded with a 7-amino-acid peptide (TR short peptide), which was used to investigate its targeting effect on brain stem cells. Compared with the unmodified micelles, the uptake rate of the TR-modified micelles was significantly increased in brain glial stem cells. TR peptide-modified micelles exhibited specific binding of the TR peptide to the CD1333 receptor, and improved anticancer effects by targeting $\mathrm{CD} 133^{+}$glioma stem cells. In conclusion, despite these studies demonstrating that CD133 can be used for the isolation and identification of LCSCs in vitro as well as for targeted therapy, the application of a single surface marker remains limited.

CD13. CD13 is the earliest identified marker of normal and malignant myeloid cells and has been used for many years to characterize and classify leukemia or lymphoma cells (72). CD13, also known as aminopeptidase $\mathrm{N}$ (73), is a zinc-binding protein. In addition, $\mathrm{CD}_{13}{ }^{+}$cells exhibit features similar to that of stem cells, such as increased cell proliferation and tumor cell formation, and increased resistance to chemotherapy. $\mathrm{CD}^{2} 3^{+}$cells are resistant to adriamycin and fluorouracil (5-FU) treatment, and expression of CD13 is enhanced by chemotherapy. This is associated with the high resistance of $\mathrm{CD}^{2} 3^{+}$cells; in the presence of chemotherapy drugs, $\mathrm{CD} 13$ cells exhibit an increased response to oxygen clusters, leading to DNA breakage and cell death. In $\mathrm{CD} 13^{+}$cells, the expression of the glutamate-cysteine ligase (GCLM) gene is significantly increased compared with other cells. GCLM catalyzes intracellular antioxidant glutathione synthesis, against reactive oxygen species induced by chemotherapy/radiotherapy, thereby protecting DNA from DNA damage, preventing apoptosis, and resulting in drug resistance (74). The classical cytotoxic antitumor drugs, doxorubicin and 5-FU, kill CD90 ${ }^{+}$ hepatoma cells, but the proportion of the surviving $\mathrm{CD}_{13}{ }^{+}$ cells increases. The percentage of $\mathrm{CD}^{+} 3^{+} / \mathrm{CD} 90^{-}$cell subpopulation in clinical tissues from patients with $\mathrm{HCC}$ who relapsed following arterial chemoembolization is significantly higher compared with untreated HCC tissues. Following administration of a low dose gradient of cyclophosphamide, the remaining tumor cells exhibit a $\mathrm{hAFP}^{+} / \mathrm{CD}^{+} 3^{+} / \mathrm{PCNA}^{-}$phenotype, with the $\mathrm{CD}_{13}{ }^{+}$cells increased, indicating that $\mathrm{CD} 13^{+}$cells are resistant to this chemotherapy. However, combined treatment with Tegafur, a prodrug of 5-fluorouracil (5-FU), and cyclophosphamide, using a low-dose rhythmic administration, significantly reduced the number of tumor cells $(75,76)$. Studies have demonstrated that the expression of CD13 may enhance the semi-static activity of CSCs. Haraguchi et al (40) observed that $\mathrm{CD} 13^{+}$cells are predominantly in the $\mathrm{G}_{1} / \mathrm{G}_{0}$ phase of the cell cycle, suggesting that $\mathrm{CD} 13$ may be a marker of the dormant or semi-stationary status of LCSCs.

Downregulation of CD13, by use of a CD13 neutralizing antibody or inhibitors, can induce apoptosis in the HCC cell lines Huh7 and PLC/PRF/5. When $\mathrm{CD} 13^{+}$hepatocytes were treated with 5-FU, which is directly targeted at CD13 molecules, the number of cells with tumorigenic and self-renewal abilities was significantly reduced (77). The coexpression of CD13 and CD90 has an important role in the occurrence of liver cancer. The combined application of CD13 and CD90 inhibitors significantly reduces tumor volume, compared with the application of each individual inhibitor alone. Reduction or inhibition of CD13 molecules on the surface of HCC cells by interfering techniques also affect, to a certain extent, the self-renewal and tumorigenic ability of LCSCs (40).

CD90 or Thy-1. In 1964, CD90 was first identified in the CH3 AKR strain mice in an effort to develop an antileukemia xenoantibody, and was named as $\theta$ antigen (78). In 1969, due to the fact that a study had demonstrated that the precursors of $\mathrm{T}$ cells 
are mature in the thymus (79), the important surface marker of T cells, $\theta$ antigen, was renamed as Thy- 1 . In the 1980s, CD90 was isolated from the human T-cell leukemia cell line, MOLT-3, indicating the presence of CD90 in humans (80). CD90 overexpression was demonstrated to be associated with age in patients with HCC and HBV infection, tissue staging and high CD90 expression were associated with poor prognosis (81). The CD90 ${ }^{+}$cell population was selected from a HCC cell line, as well as tissues and blood from patients with $\mathrm{HCC}$, and it was demonstrated that they presented increased tumorigenic abilities and indefinite proliferation compared with the CD90- cell population, suggesting that the $\mathrm{CD} 90^{+}$cells might be a 'hepatocellular stem cell' population $(48,82)$. CD90 is a surface marker expressed in human HCC cell lines and mesenchymal stem cells with a positive rate of $\sim 0-2.5 \%$, and often serves as a surface marker for various stem cells. Yang et al (48) noted that HCC tumor samples and the majority of blood samples contain highly tumorigenic $\mathrm{CD} 90^{+} / \mathrm{CD} 45^{-}$cells, while samples from normal individuals or patients with chronic hepatitis do not. Similarly, aspects of the aforementioned study, which focused on the expression of CD90 in HCC cell lines, revealed that only $\mathrm{CD} 90^{+}$cells exhibited tumorigenic ability. If the surface marker glycoprotein CD44 was also expressed in the $\mathrm{CD} 90^{+}$cells, the invasive phenotype was even stronger, with increased metastatic and self-renewal capacities. When CD44 was blocked by an inhibiting antibody, the tumor formation and metastasis abilities of CD90 ${ }^{+}$cells were decreased and apoptosis was induced. In the same study, it was also noted that $\mathrm{CD} 45^{-} / \mathrm{CD} 0^{+}$cells were present in all tissue samples and $\sim 90 \%$ of blood samples from liver cancer patients, and exhibited a more aggressive phenotype in immunodeficient mice; while only a small population of $\mathrm{CD} 90^{+}$cells existed among 6 different liver cancer cell lines, and exhibited a low aggressive phenotype in immunodeficient mice. Transplant experiments in nude mice demonstrated that $\mathrm{CD} 90^{+} \mathrm{HCC}$ cells had a tumorigenic ability that was not present in the CD90- cells. A further study has indicated that $\mathrm{CD} 45^{-} / \mathrm{CD} 90^{+}$cells also express other stem cell markers, including CD133, epithelial specific antigen (ESA), CXCR4, CD24, kinase insert domain receptor and CD44 (48). CD90, possibly one of the surface markers of LCSCs, has been used in the identification of LCSCs in recent years. CD45/CD90 ${ }^{+}$cells may become a new target for diagnosis and treatment of liver cancer. CD90 has been shown to upregulate the expression of the molecular marker CD133, and this abnormal expression can promote tumor progression. The CD90/integrin/mechanistic target of rapamycin kinase (mTOR)/AMP-activated protein kinase (AMPK)/CD133 signaling pathway serves an important role in tumor formation, and inhibition of this pathway by the energy-limited simulant, OSU-CG5, reduced the proportion of $\mathrm{CD} 90^{+}$cells in fresh HCC specimens and inhibited tumor growth (83).

CD44. CD44 is a glycoprotein encoded by a single gene, and hyaluronic acid is its main receptor. As an important class of adhesion molecules, CD44 is widely distributed on the cell surface of various cell types, including lymphocytes, monocytes and endothelial cells (84), and it is involved in intercellular cell adhesion and cell migration. CD44 may be associated with tumor cell invasion and metastasis of liver cancer (36).
Under normal circumstances, CD44 is in a relatively quiescent state on the cell surface. However, CD44 is overexpressed in tumor cells and mainly involved in heterotypic adhesion (the adhesion of tumor cells to the host cells and the host matrix), thereby promoting tumor cell invasion and metastasis. The relationship between CD44 and tumor infiltration and metastasis has been investigated (85). CD44 is a stem cell marker of pancreatic, gastric, and colorectal cancer. Subsequent studies indicated that it is also one of the important markers of LCSCs, and its coexpression with other markers can better identify LCSC phenotypes. Mima et al (49) observed in a nude mouse model that the tumor formation rate of $\mathrm{CD} 44^{+}$cells was faster compared with $\mathrm{CD} 44^{-}$cells, and that only $\mathrm{CD} 90^{+} / \mathrm{CD} 44^{+}$ cells appeared in the lung metastasis sites. Compared with $\mathrm{CD} 133^{+} / \mathrm{CD}_{4} 4^{-}$cells, $\mathrm{CD} 133^{+} / \mathrm{CD} 44^{+} \mathrm{HCC}$ cells were more prone to tumor formation and drug resistance, and expressed more stem-associated genes (36). $\mathrm{CD} 133^{+} / \mathrm{CD} 90^{+}$cells were more aggressive than $\mathrm{CD}_{4} 4^{+}$cells alone.

Blocking CD44 activity by use of a CD44-targeting antibody can induce the apoptosis of $\mathrm{CD}^{+} 0^{+}$cells in vitro and inhibit tumor formation of $\mathrm{CD}^{+}$cells in immunodeficient mice in vivo (86). IM7 is a murine monoclonal antibody specifically targeting CD44, which has a confirmed inhibitory effect on tumor growth. Zhang et al (87) reported that RG7356, a humanized antibody against CD44, could induce apoptosis of chronic lymphocytic leukemia cells.

To date, given the characteristics of CD44, studies on short peptides targeting CD44 are gradually increasing. Cho et al (88) prepared a novel short peptide complex PDPP targeting CD44 by combining the short peptide with D-polylysine. The binding capacity of PDPP and CD44 was 4-10 times stronger than that of the CD44 antibody, suggesting that PDPP may serve as a probe for the diagnosis and treatment of cancer stem cells. Park et al (89) successfully identified a short peptide, P7(FNLPLPSRPLLR), which can specifically bind to CD44 expressed on the surface of breast cancer CSCs. Similar to the CD44 antibody, the binding rate of P7 on MCF7 cells was high. Therefore, the authors suggest that the short peptide $\mathrm{P} 7$ could be used for the treatment of CSCs as a substitute for antibodies.

EpCAM. EpCAM is a transmembrane glycoprotein with a relative molecular mass of 40,000 Da and currently used in research for various tumor types (90-93). EpCAM is expressed during the early liver development process, but not in normal mature liver cells. EpCAM is expressed in human epithelial tissue and tumors, as well as in precursor cells and stem cells. It is also present in liver stem cells and hepatoblasts. Nevertheless, the high expression of EpCAM is significantly associated with activation of cell proliferation (94). EpCAM is also expressed on the surface of LCSCs and pancreatic CSCs $(95,96)$. Recent studies have demonstrated that the tumor formation and invasion abilities of EpCAM ${ }^{+} \mathrm{HCC}$ cells were significantly higher compared with EpCAM ${ }^{-} \mathrm{HCC}$ cells (97). Liver stem cell surface markers were expressed in $\mathrm{EpCAM}^{+}$cells, while the expression of mature hepatocyte markers was significantly increased in EpCAM- cells (91). Yamashita et al (98), EpCAM expression was utilized to classify patients with HCC, and the differential expression of AFP and EpCAM was verified in tumor samples from two HCC cell lines. EpCAM ${ }^{+}$cells 
exhibited CSC-like characteristics, with high tumor formation ability in vivo and in vitro. Compared with EpCAM- cells, the increased CSC characteristics of $\mathrm{EpCAM}^{+}$cells in primary liver cancer samples were further confirmed. The aforementioned study indicated that activation of the Wnt/ $\beta$-catenin signaling pathway may increase the proportion of $\mathrm{EpCAM}^{+}$ cells and block the reduction of EpCAM-induced tumorigenic ability of these cells. Results of CD90 and EpCAM expression obtained from HCC tumor cell lines were confirmed in human HCC samples. The aforementioned studies offer direct evidence for the existence of LCSCs in human HCC.

Targeted therapy towards the LCSC molecular marker EpCAM can effectively eliminate the expression of EpCAM in LCSCs $(99,100)$. EpCAM antibodies currently available in preclinical or clinical studies include edrecolomab, adecatumumab, MT110 and catumaxomab, and they have been approved in the EU for patients with $\mathrm{EpCAM}^{+}$malignant ascites. Chen et al (7) used an EpCAM antibody (EpCAM-Ab) as the target to modify micelles loaded with anticancer drugs or genes, and to develop a gene delivery system targeting CSCs. This delivery system exhibited characteristics of $\mathrm{pH}$-responsive drug release, with the amount of drug released at $\mathrm{pH} 5.0$ being $40 \%$ higher than that at $\mathrm{pH}$ 7.4. In vitro experiments showed that the inhibitory effect of EpCAMAb-modified adriamycin-loaded micelles on LCSCs was significantly enhanced, with an $\mathrm{IC}_{50}$ of $0.051 \mathrm{mg} / 1$, while the $\mathrm{IC}_{50}$ of the EpCAMAb-unmodified adriamycin-loaded micelles was $0.24 \mathrm{mg} / \mathrm{l}$, which was 5 times that of the former. This targeted drug delivery system offers a significant therapeutic effect, indicating the feasibility of this antibody-mediated active CSC targeted therapy, as well as its potential value for the clinical treatment of cancer. Because RNA interference (RNAi) of EpCAM has been confirmed to significantly reduce the number of stem cells and their tumorigenic and invasive abilities (91,95), Bae et al (101) reported that, following EpCAM gene silencing by RNAi, HCC tumor grade, proliferation, invasiveness and AFP levels were significantly decreased.

\section{Other LCSC targets and their applications in tumor therapy}

Delta-like 1 non-canonical Notch ligand 1 (DLK1) is a progenitor marker in fetal liver and serves an important role in the carcinogenesis of HCC. Tanimizu et al (102) in order to isolate and characterize hepatobrobocytes, used the signal sequence trap method to search for cell surface antigens expressed in mouse fetal hepatocytes. They demonstrated that DLK1 (also known as Pref-1) was highly expressed in fetal liver and reported that most of the colony-forming $\mathrm{DLK} 1^{+}$cells could differentiate into hepatocytes and bile duct epithelial cells. In addition, $7 \%$ of the colony-forming $\mathrm{DLK}^{+}$cells exhibited a high degree of proliferation, and were able to form a large colony containing $>100$ cells following 5 days in culture. When they transplanted donor $\mathrm{DLK} 1^{+}$cells into recipient spleens, they found donor-derived hepatocytes in the recipient liver, indicating that $\mathrm{DLK}^{+}$cells were able to differentiate into hepatocytes in vivo. These results clearly suggest that DLK1 is a liver hepatocyte marker (102). The biological behavioral differences between DLK1 ${ }^{+}$and DLK1' cells were assessed by growth curve, colony formation assay, spherical colony formation, chemical resistance and in vivo tumorigenicity. Knockdown of DLK1 reduced the malignancy of HCC cells and may kill LCSCs directly (103), suggesting that DLK1 may be a potential therapeutic target for LCSCs.

Assis et al (104) reported that $\mathrm{CD} 24^{+} \mathrm{HCC}$ cells were highly important in the maintenance, self-renewal, differentiation and metastasis of chemotherapy-tolerant HCC cell xenografts, significantly affected the clinical prognosis, and tumor recurrence following chemotherapy. The authors used experiments based on lentivirus knockdowns and demonstrated that CD24 is a functional LCSC marker that is regulated by signal transducer and activator of transcription 3-mediated NANOG homeobox regulation to generate CSCs. These results suggested that the CD24 cascade in LCSCs may provide an attractive therapeutic target for HCC.

De Francesco et al (105) isolated the population of cells with CSC properties and labeled the calcium channel $\alpha 2 \delta 1$ in primary hepatocellular carcinoma and their surgical margins using the monoclonal antibody 1B50-1. It was demonstrated that $\alpha 2 \delta 1$ serves an important role in regulating the calcium oscillation amplitude, which is important in maintaining the properties of CSCs. 1B50-1 can bind $\alpha 2 \delta 1$ in CSCs and may have potential as a drug against HCC by targeting $\alpha 2 \delta 1$.

Recent studies have demonstrated that ICAM-1 is expressed on a variety of stem cells, including bone marrow mesenchymal stem cells, adipose-derived stem cells, periodontal ligament stem cells and placental mesenchymal stem cells (103-106). Based on the above findings, intercellular adhesion molecule-1 (ICAM-1) is also considered to be one of the surface markers of LCSCs. Liu et al (107) measured the sphere formation and tumor formation abilities of ICAM- $1^{+}$ cells in vivo and in vitro, respectively. They also used a specific targeting system that inhibited ICAM-1 expression in HBV transgenic mice (M-TgHBV) to study whether inhibition of ICAM-1 expression reduced the incidence and metastasis of tumors in vivo. ICAM-1 was demonstrated to be significantly expressed in HCC tumor cell lines, tumor tissue from patients or transgenic mice, and in circulating tumor cells from patients. Compared with ICAM-1- tumor cells, ICAM-1+ $1^{+}$tumor cells exhibited greater tumorigenic ability and increased expression of stem cell-related genes. Specific inhibition of ICAM-1 reduced tumor formation and metastasis in $\mathrm{M}-\mathrm{TgHBV}$ mice. Increased numbers of CD45/ICAM- $1^{+}$cells in blood samples from patients with HCC was an indicator of poor prognosis. Finally, this review also reported that ICAM-1 expression was regulated by the stem cell transcription factor Nanog.

Barclay and Brown (108) reported that CD47, a widely expressed integrin-related protein, was upregulated in LCSCs. Since CD47 acts as a ligand for signal-regulatory protein $\alpha(\operatorname{SIRP} \alpha)$, which is mainly expressed on phagocytic cells (including macrophages and dendritic cells), the activation of CD47 receptors can initiate a signal transduction cascade and inhibit macrophage cell phagocytosis (108-112). Majeti et al (113) demonstrated that CD47 expression in leukemia stem cells was increased compared with normal controls, and high expression of CD47 was associated with poor overall survival in three independent adult AML patients. In addition, the monoclonal antibody CD47 can cause leukemia stem cells to be engulfed by macrophages. Anti-CD47 antibody was used to target AML LSC in human 
AML LSC-transplanted mice, and the results demonstrated that high expression of CD47 is an independent factor indicating poor prognosis, and may be used as a target for the treatment of AML. Chao et al (114) demonstrated that calreticulin is a major pre-phagocytic signal in several human cancers. It provides an explanation for the role of anti-CD47 antibody in selectively targeting tumor cells and highlights the balance between phagocytosis and anti-phagocytosis in hepatocellular carcinoma immune escape. Willingham et al (115) blocked CD47 by use of targeting monoclonal antibodies and demonstrated that inhibition of macrophage phagocytosis by CD47 was relieved in in vitro experiments. Then, they established a tumor model by transplanting human tumor cells into immunodeficient mice, and treated them with the anti-CD47 antibody. The results indicated that increased treatment duration extended survival in mice. Treatment of larger tumors with the anti-CD47 antibody inhibited tumor growth and metastasis. Anti-CD47 antibodies have potential effects on the treatment of smaller tumors, as well. The results demonstrated that all human tumor cells require the expression of CD47 to inhibit the innate immune monitoring and clearance of phagocytic cells, while CD47 is a widely expressed marker in all cancers that help tumor cells escape from phagocytosis and clearance. Thus, CD47 may be an effective target for the treatment of cancer. Lee et al (116) revealed that transplantation of freshly isolated $\mathrm{CD} 47^{+}$cells in non-obese diabetic/severe combined immunodeficiency (NOD/SCID) mice exhibit strong tumorigenicity, self-renewal and distant metastasis. CD47 mRNA is preferentially expressed in $\mathrm{CD} 133^{+} / \mathrm{CD} 24^{+}$ LCSCs. In addition, the increased expression level of CD47 mRNA in HCC clinical samples is positively correlated with patient survival. Knockout of CD47 using lentivirus-based short hairpin RNA (shRNA) inhibited the characteristics of stem cells, suggesting that $\mathrm{CD} 47$ has a key role in regulating the stem cell characteristics of HCC. In addition, cathepsin S (CTSS) is a downstream effector of CD47, which is preferentially secreted by $\mathrm{CD} 47^{+} \mathrm{HCC}$ cells and could regulate the function of hepatic CSCs by activating protease-activated receptor 2 (PAR2) through autocrine pathways. Clinically, the serum level of CTSS was significantly associated with advanced tumor behavior in human HCC. HCC cell lines and patient-derived xenograft models were established and the CTSS/PAR2 signaling pathway was blocked by the morpholino approach to achieve chemosensitization effects. This review elucidates the signal transduction function of CD47 and its role in the pathogenesis of cancer through the CTSS/PAR2 pathway, suggesting a novel target in HCC treatment.

Lei et al (117) used the lysine-specific demethylase $1 \mathrm{~A} /$ prickle planar cell polarity protein 1 /adenomatous polyposis coli/ $\beta$-catenin signal axis as a novel molecular circuit to regulate the hepatocyte properties and chemoresistance of $\mathrm{Lgr}^{+} \mathrm{LCSC}$ in liver, and the results confirmed that this signal axis may be used as a target for chemotherapy sensitization of liver cancer.

\section{Conclusions and perspectives}

Given the lack of sensitivity of liver cancer to radiochemotherapy, current treatments of liver cancer include surgical procedures, interventional therapy (including TACE, microwave ablation, and particle implantation therapy), and biological therapy (including immunotherapy and gene therapy). However, even surgery-based comprehensive treatment cannot prevent HCC recurrence and metastasis. Exploration of possible targeted therapies towards LCSCs may offer the only way to break through the bottleneck of HCC treatment. Current targeted therapy strategies for HCC include the inhibition of LCSC proliferation and induction of apoptosis; induction of LCSC differentiation to improve sensitivity to radiochemotherapy; and destruction of the LCSC microenvironment. Furthermore, direct targeting of LCSC surface markers, including CD133, CD90 and EpCAM, may represent another research direction. Although the molecular targeted drug, sorafenib, alone or in combination may inhibit the progress of HCC, drug resistance occurs fast and the numbers of $\mathrm{CD} 90^{+}$cells are not reduced. Therefore, radical treatment of HCC should begin by eliminating the stem cells. Although various LCSC surface markers have been identified, LCSCs of high purity cannot be independently isolated using only one molecular marker, and some regulation mechanisms of stem cells remain unclear. Findings on LCSCs have been mainly obtained from in vitro experiments. Without examining the role of LCSCs within their microenvironment in the body, it is unclear whether the direct application of these results to the human body will work effectively. Further studies are therefore urgently required in order to develop efficient novel treatments for liver cancer.

\section{References}

1. Fan ST, Mau Lo C, Poon RT, Yeung C, Leung Liu C, Yuen WK, Ming LC, Ng KK and Ching Chan S: Continuous improvement of survival outcomes of resection of hepatocellular carcinoma: A 20-year experience. Ann Surg 253: 745-758, 2011.

2. Bruix J and Sherman M; American Association for the Study of Liver Diseases: Management of hepatocellular carcinoma: An update. Hepatology 53: 1020-1022, 2011.

3. Woerns MA and Galle PR: Future perspectives in hepatocellular carcinoma. Digest Liver Dis 42 (Suppl 3): S302-S309, 2010.

4. Rountree CB, Mishra L and Willenbring H: Stem cells in liver diseases and cancer: Recent advances on the path to new therapies. Hepatology 55: 298-306, 2012.

5. Ji J and Wang XW: Clinical implications of cancer stem cell biology in hepatocellular carcinoma. Semin Oncol 39: 461-472, 2012.

6. Skubitz AP, Taras EP, Boylan KL, Waldron NN, Oh S, Panoskaltsis-Mortari A and Vallera DA: Targeting CD133 in an in vivo ovarian cancer model reduces ovarian cancer progression. Gynecol Oncol 130: 579-587, 2013.

7. Chen J, Liu Q, Xiao J and Du J: EpCAM-antibody-labeled noncytotoxic polymer vesicles for cancer stem cells-targeted delivery of anticancer drug and siRNA. Biomacromolecules 16: 1695-1705, 2015.

8. Lawson DA, Bhakta NR, Kessenbrock K, Prummel KD, Yu Y, Takai K, Zhou A, Eyob H, Balakrishnan S, Wang CY, et al: Single-cell analysis reveals a stem-cell program in human metastatic breast cancer cells. Nature 526: 131-135, 2015.

9. Yang Y, Fan Y, Qi Y, Liu D, Wu K, Wen F and Zhao S: Side population cells separated from A549 lung cancer cell line possess cancer stem cell-like properties and inhibition of autophagy potentiates the cytotoxic effect of cisplatin. Oncol Rep 34: 929-935, 2015

10. Iacopino F, Angelucci C, Piacentini R, Biamonte F, Mangiola A, Maira G, Grassi C and Sica G: Isolation of cancer stem cells from three human glioblastoma cell lines: Characterization of two selected clones. Plos One 9: e105166, 2014.

11. Steiner JW, Perz ZM and Taichman LB: Cell population dynamics in the liver. A review of quantitative morphological techniques applied to the study of physiological and pathological growth. Exp Mol Pathol 5: 146-181, 1966. 
12. Turner R, Lozoya O, Wang Y, Cardinale V, Gaudio E, Alpini G, Mendel G, Wauthier E, Barbier C, Alvaro D and Reid LM: Human hepatic stem cell and maturational liver lineage biology. Hepatology 53: 1035-1045, 2011.

13. Wang X, Foster M, Al-Dhalimy M, Lagasse E, Finegold M and Grompe M: The origin and liver repopulating capacity of murine oval cells. Proc Natl Acad Sci USA 100 (Suppl 1): S11881-S11888, 2003.

14. Libbrecht L, De Vos R, Cassiman D, Desmet V, Aerts R and Roskams T: Hepatic progenitor cells in hepatocellular adenomas. Am J Surg Pathol 25: 1388-1396, 2001.

15. Crosby HA, Hubscher SG, Joplin RE, Kelly DA and Strain AJ: Immunolocalization of OV-6, a putative progenitor cell marker in human fetal and diseased pediatric liver. Hepatology 28 : 980-985, 1998

16. Yang W, Yan HX, Chen L, Liu Q, He YQ, Yu LX, Zhang SH, Huang DD, Tang L, Kong XN, et al: Wnt/beta-catenin signaling contributes to activation of normal and tumorigenic liver progenitor cells. Cancer Res 68: 4287-4295, 2008

17. Yang W, Wang C, Lin Y, Liu Q, Yu LX, Tang L, Yan HX, Fu J, Chen Y, Zhang HL, et al: $\mathrm{OV}^{+}$tumor-initiating cells contribute to tumor progression and invasion in human hepatocellular carcinoma. J Hepatol 57: 613-620, 2012.

18. Navarro-Alvarez N, Soto-Gutierrez A and Kobayashi N: Hepatic stem cells and liver development. Methods Mol Biol 640: 181-236, 2010

19. Clarke MF, Dick JE, Dirks PB, Eaves CJ, Jamieson CH, Jones DL, Visvader J, Weissman IL and Wahl GM: Cancer stem cells-perspectives on current status and future directions: AACR Workshop on cancer stem cells. Cancer Res 66 : 9339-9344, 2006

20. Chiba T, Kita K, Zheng YW, Yokosuka O, Saisho H, Iwama A, Nakauchi $\mathrm{H}$ and Taniguchi $\mathrm{H}$ : Side population purified from hepatocellular carcinoma cells harbors cancer stem cell-like properties. Hepatology 44: 240-251, 2006.

21. Liu LL, Fu D, Ma Y and Shen XZ: The power and the promise of liver cancer stem cell markers. Stem Cells Dev 20: 2023-2030, 2011

22. Gournay J, Auvigne I, Pichard V, Ligeza C, Bralet MP and Ferry N: In vivo cell lineage analysis during chemical hepatocarcinogenesis in rats using retroviral-mediated gene transfer: Evidence for dedifferentiation of mature hepatocytes. Lab Invest 82: 781-788, 2002.

23. Sell S: Heterogeneity and plasticity of hepatocyte lineage cells. Hepatology 33: 738-750, 2001.

24. Dumble ML, Croager EJ, Yeoh GC and Quail EA: Generation and characterization of p53 null transformed hepatic progenitor cells: Oval cells give rise to hepatocellular carcinoma. Carcinogenesis 23: 435-445, 2002.

25. Michalopoulos GK and DeFrances MC: Liver regeneration. Science 276: 60-66, 1997

26. Shafritz DA, Oertel M, Menthena A, Nierhoff D and Dabeva MD Liver stem cells and prospects for liver reconstitution by transplanted cells. Hepatology 43: S89-S98, 2006.

27. Yao Z and Mishra L: Cancer stem cells and hepatocellular carcinoma. Cancer Biol Ther 8: 1691-1698, 2009.

28. Durnez A, Verslype C, Nevens F, Fevery J, Aerts R, Pirenne J, Lesaffre E, Libbrecht L, Desmet V and Roskams T: The clinicopathological and prognostic relevance of cytokeratin 7 and 19 expression in hepatocellular carcinoma. A possible progenitor cell origin. Histopathology 49: 138-151, 2006

29. Yeh CT, Kuo CJ, Lai MW, Chen TC, Lin CY, Yeh TS and Lee WC: CD133-positive hepatocellular carcinoma in an area endemic for hepatitis B virus infection. BMC Cancer 9: 324, 2009.

30. Okumoto K, Saito T, Haga H, Hattori E, Ishii R, Karasawa T, Suzuki A, Misawa K, Sanjo M, Ito JI, et al: Characteristics of rat bone marrow cells differentiated into a liver cell lineage and dynamics of the transplanted cells in the injured liver. J Gastroenterol 41: 62-69, 2006.

31. Haraguchi N, Utsunomiya T, Inoue H, Tanaka F, Mimori K, Barnard GF and Mori M: Characterization of a side population of cancer cells from human gastrointestinal system. Stem Cells 24: 506-513, 2006

32. Jordan CT, Guzman ML and Noble M: Cancer stem cells. N Engl J Med 355: 1253-1261, 2006.

33. Maugeri-Saccà $M$, Vigneri $P$ and De Maria R: Cancer stem cells and chemosensitivity. Clin Cancer Res 17: 4942-4947, 2011

34. Hu C, Li H, Li J, Zhu Z, Yin S, Hao X, Yao M, Zheng S and Gu J: Analysis of ABCG2 expression and side population identifies intrinsic drug efflux in the HCC cell line MHCC-97L and its modulation by Akt signaling. Carcinogenesis 29: 2289-2297, 2008
35. Ma S, Chan KW, Lee TK, Tang KH, Wo JY, Zheng BJ and Guan XY: Aldehyde dehydrogenase discriminates the CD133 liver cancer stem cell populations. Mol Cancer Res 6: 1146-1153, 2008.

36. Zhu Z, Hao X, Yan M, Yao M, Ge C, Gu J and Li J: Cancer stem/progenitor cells are highly enriched in $\mathrm{CD} 133^{+} \mathrm{CD} 44^{+}$ population in hepatocellular carcinoma. Int J Cancer 126 2067-2078, 2010

37. Ma S, Lee TK, Zheng BJ, Chan KW and Guan XY: $\mathrm{CD}_{133^{+}} \mathrm{HCC}$ cancer stem cells confer chemoresistance by preferential expression of the Akt/PKB survival pathway. Oncogene 27: 1749-1758, 2008.

38. Piao LS, Hur W, Kim TK, Hong SW, Kim SW, Choi JE, Sung PS, Song MJ, Lee BC, Hwang D and Yoon SK: CD133+ liver cancer stem cells modulate radioresistance in human hepatocellular carcinoma. Cancer Lett 315: 129-137, 2012.

39. Xin HW, Ambe CM, Hari DM, Wiegand GW, Miller TC, Chen JQ, Anderson AJ, Ray S, Mullinax JE, Koizumi T, et al: Label-retaining liver cancer cells are relatively resistant to sorafenib. Gut 62: 1777-1786, 2013.

40. Haraguchi N, Ishii H, Mimori K, Tanaka F, Ohkuma M, Kim HM, Akita H, Takiuchi D, Hatano H, Nagano H, et al: CD13 is a therapeutic target in human liver cancer stem cells. J Clin Invest 120: 3326-3339, 2010.

41. Ma S, Tang KH, Chan YP, Lee TK, Kwan PS, Castilho A, Ng I, Man K, Wong N, To KF, et al: miR-130b promotes CD133(+) liver tumor-initiating cell growth and self-renewal via tumor protein 53-induced nuclear protein 1. Cell Stem Cell 7: 694-707, 2010.

42. Zhang J, Luo N, Luo Y, Peng Z, Zhang T and Li S: MicroRNA-150 inhibits human CD133-positive liver cancer stem cells through negative regulation of the transcription factor $\mathrm{c}-\mathrm{Myb}$. Int $\mathrm{J}$ Oncol 40: 747-756, 2012.

43. Fan ST, Yang ZF, Ho DW, Ng MN, Yu WC and Wong J: Prediction of posthepatectomy recurrence of hepatocellular carcinoma by circulating cancer stem cells: A prospective study. Ann Surg 254: 569-576, 2011.

44. Philip PA, Mooney M, Jaffe D, Eckhardt G, Moore M, Meropol N, Emens L, O'Reilly E, Korc M, Ellis L, et al: Consensus report of the national cancer institute clinical trials planning meeting on pancreas cancer treatment. J Clin Oncol 27: 5660-5669, 2009

45. Park CY, Tseng D and Weissman IL: Cancer stem cell-directed therapies: Recent data from the laboratory and clinic. Mol Ther 17: 219-230, 2009.

46. Yamashita T, Honda M, Nakamoto Y, Baba M, Nio K, Hara Y, Zeng SS, Hayashi T, Kondo M, Takatori H, et al: Discrete nature of EpCAM ${ }^{+}$and CD90 ${ }^{+}$cancer stem cells in human hepatocellular carcinoma. Hepatology 57: 1484-1497, 2013.

47. Ma S, Chan KW, Hu L, Lee TK, Wo JY, Ng IO, Zheng BJ and Guan XY: Identification and characterization of tumorigenic liver cancer stem/progenitor cells. Gastroenterology 132: 2542-2556, 2007.

48. Yang ZF, Ho DW, Ng MN, Lau CK, Yu WC, Ngai P, Chu PW, Lam CT, Poon RT and Fan ST: Significance of CD90 cancer stem cells in human liver cancer. Cancer Cell 13: 153-166, 2008.

49. Mima K, Okabe H, Ishimoto $T$, Hayashi $H$, Nakagawa $S$, Kuroki H, Watanabe M, Beppu T, Tamada M, Nagano O, et al: $\mathrm{CD} 44 \mathrm{~s}$ regulates the TGF- $\beta$-mediated mesenchymal phenotype and is associated with poor prognosis in patients with hepatocellular carcinoma. Cancer Res 72: 3414-3423, 2012.

50. Wilson GS, Hu Z, Duan W, Tian A, Wang XM, McLeod D, Lam V, George J and Qiao L: Efficacy of using cancer stem cell markers in isolating and characterizing liver cancer stem cells. Stem Cells Dev 22: 2655-2664, 2013.

51. Singh SK, Clarke ID, Terasaki M, Bonn VE, Hawkins C, Squire J and Dirks PB: Identification of a cancer stem cell in human brain tumors. Cancer Res 63: 5821-5828, 2003.

52. Bonnet D and Dick JE: Human acute myeloid leukemia is organized as a hierarchy that originates from a primitive hematopoietic cell. Nat Med 3: 730-737, 1997.

53. Fang D, Nguyen TK, Leishear K, Finko R, Kulp AN, Hotz S, Van Belle PA, Xu X, Elder DE and Herlyn M: A tumorigenic subpopulation with stem cell properties in melanomas. Cancer Res 65: 9328-9337, 2005.

54. Suetsugu A, Nagaki M, Aoki H, Motohashi T, Kunisada T and Moriwaki H: Characterization of $\mathrm{CD}_{133^{+}}$hepatocellular carcinoma cells as cancer stem/progenitor cells. Biochem Biophys Res Commun 351: 820-824, 2006. 
55. Tchoghandjian A, Baeza N, Colin C, Cayre M, Metellus $\mathrm{P}$, Beclin C, Ouafik L and Figarella-Branger D: A2B5 cells from human glioblastoma have cancer stem cell properties. Brain Pathol 20: 211-221, 2010.

56. Miraglia S, Godfrey W, Yin AH, Atkins K, Warnke R, Holden JT, Bray RA, Waller EK and Buck DW: A novel five-transmembrane hematopoietic stem cell antigen: Isolation, characterization and molecular cloning. Blood 90: 5013-5021, 1997.

57. Shmelkov SV, Jun L, St Clair R, McGarrigle D, Derderian CA, Usenko JK, Costa C, Zhang F, Guo X and Rafii S: Alternative promoters regulate transcription of the gene that encodes stem cell surface protein AC133. Blood 103: 2055-2061, 2004.

58. Cioffi M, D'Alterio C, Camerlingo R, Tirino V, Consales C Riccio A, Ieranó C, Cecere SC, Losito NS, Greggi S, et al: Identification of a distinct population of CD133(+)CXCR4(+) cancer stem cells in ovarian cancer. Sci Rep 5: 10357, 2015

59. Swaminathan SK, Roger E, Toti U, Niu L, Ohlfest JR and Panyam J: CD133-targeted paclitaxel delivery inhibits local tumor recurrence in a mouse model of breast cancer. J Control Release 171: 280-287, 2013.

60. Rountree CB, Ding W, He L and Stiles B: Expansion of CD133-expressing liver cancer stem cells in liver-specific phosphatase and tensin homolog deleted on chromosome 10-deleted mice. Stem Cells 27: 290-299, 2009.

61. Yin S, Li J, Hu C, Chen X, Yao M, Yan M, Jiang G, Ge C, Xie H, Wan D, et al: CD133 positive hepatocellular carcinoma cells possess high capacity for tumorigenicity. Int J Cancer 120 : 1444-1450, 2007.

62. Kohga K, Tatsumi T, Takehara T, Tsunematsu H, Shimizu S, Yamamoto M, Sasakawa A, Miyagi T and Hayashi N: Expression of CD133 confers malignant potential by regulating metalloproteinases in human hepatocellular carcinoma. J Hepatol 52: 872-879, 2010

63. YaoJ,Zhang T,Ren J,Yu Mand Wu G: Effect of CD133/prominin-1 antisense oligodeoxynucleotide on in vitro growth characteristics of Huh-7 human hepatocarcinoma cells and U251 human glioma cells. Oncol Rep 22: 781-787, 2009.

64. Song W, Li H, Tao K, Li R, Song Z, Zhao Q, Zhang F and Dou K: Expression and clinical significance of the stem cell marker CD133 in hepatocellular carcinoma. Int J Clin Pract 62 1212-1218, 2008.

65. Salnikov AV, Kusumawidjaja G, Rausch V, Bruns H, Gross W, Khamidjanov A, Ryschich E, Gebhard MM, Moldenhauer G Büchler MW, et al: Cancer stem cell marker expression in hepatocellular carcinoma and liver metastases is not sufficient as single prognostic parameter. Cancer Lett 275: 185-193, 2009.

66. Li J, Chen JN, Zeng TT, He F, Chen SP, Ma S, Bi J, Zhu XF and Guan XY: CD133+ ${ }^{+}$liver cancer stem cells resist interferon-gamma-induced autophagy. BMC Cancer 16: 15, 2016.

67. Prasad S, Gaedicke S, Machein M, Mittler G, Braun F, Hettich M, Firat E, Klingner K, Schuler J, Wider D, et al: Effective eradication of glioblastoma stem cells by local application of an AC133/CD133-specific T-cell-engaging antibody and CD8 T cells. Cancer Res 75: 2166-2176, 2015.

68. Smith LM, Nesterova A, Ryan MC, Duniho S, Jonas M, Anderson M, Zabinski RF, Sutherland MK, Gerber HP, Van Orden KL, et al: CD133/prominin-1 is a potential therapeutic target for antibody-drug conjugates in hepatocellular and gastric cancers. Br J Cancer 99: 100-109, 2008.

69. Lang J, Lan X, Liu Y, Jin X, Wu T, Sun X, Wen Q and An R: Targeting cancer stem cells with an 131I-labeled anti-AC133 monoclonal antibody in human colorectal cancer xenografts. Nucl Med Biol 42: 505-512, 2015

70. Sun J, Zhang C, Liu G, Liu H, Zhou C, Lu Y, Zhou C, Yuan L and $\mathrm{Li} \mathrm{X}$ : A novel mouse CD133 binding-peptide screened by phage display inhibits cancer cell motility in vitro. Clin Exp Metastasis 29: 185-196, 2012

71. Wang $\mathrm{J}$ and Zhang Q: Targeting glioblastoma cancer stem cell marker CD133 by heptapeptide-modified DSPE-PEG micelles. J Chin Pharm Sci 24, 2015.

72. Ashmun RA and Look AT: Metalloprotease activity of CD13/aminopeptidase $\mathrm{N}$ on the surface of human myeloid cells. Blood 75: 462-469, 1990.

73. Look AT, Ashmun RA, Shapiro LH and Peiper SC: Human myeloid plasma membrane glycoprotein CD13 (gp150) is identical to aminopeptidase N. J Clin Invest 83: 1299-1307, 1989.
74. Bralet MP, Pichard V and Ferry N: Demonstration of direct lineage between hepatocytes and hepatocellular carcinoma in diethylnitrosamine-treated rats. Hepatology 36: 623-630, 2002

75. Guzman-Rojas L, Rangel R, Salameh A, Edwards JK, Dondossola E, Kim YG, Saghatelian A, Giordano RJ, Kolonin MG, Staquicini FI, et al: Cooperative effects of aminopeptidase N (CD13) expressed by nonmalignant and cancer cells within the tumor microenvironment. Proc Natl Acad Sci USA 109: 1637-1642, 2012.

76. Munoz R, Man S, Shaked Y, Lee CR, Wong J, Francia G and Kerbel RS: Highly efficacious nontoxic preclinical treatment for advanced metastatic breast cancer using combination oral UFT-cyclophosphamide metronomic chemotherapy. Cancer Res 66: 3386-3391, 2006

77. Christ B, Stock P and Dollinger MM: CD13: Waving the flag for a novel cancer stem cell target. Hepatology 53: 1388-1390, 2011.

78. Reif AE and Allen JM: The AKR thymic antigen and its distribution in leukemias and nervous tissues. J Exp Med 120: 413-433, 1964.

79. Schlesinger M and Yron I: Antigenic changes in lymph-node cells after administration of antiserum to thymus cells. Science 164: $1412-1413,1969$

80. Ades EW, Zwerner RK, Acton RT and Balch CM: Isolation and partial characterization of the human homologue of Thy-1. J Exp Med 151: 400-406, 1980.

81. Lu JW, Chang JG, Yeh KT, Chen RM, Tsai JJ and Hu RM: Overexpression of Thy1/CD90 in human hepatocellular carcinoma is associated with HBV infection and poor prognosis. Acta Histochem 113: 833-838, 2011.

82. Yang ZF, Ngai P, Ho DW, Yu WC, Ng MN, Lau CK, Li ML, Tam KH, Lam CT, Poon RT and Fan ST: Identification of local and circulating cancer stem cells in human liver cancer. Hepatology 47: 919-928, 2008

83. Chen WC, Chang YS, Hsu HP, Yen MC, Huang HL, Cho CY, Wang CY, Weng TY, Lai PT, Chen CS, et al: Therapeutics targeting CD90-integrin-AMPK-CD133 signal axis in liver cancer. Oncotarget 6: 42923-42937, 2015.

84. Noto Z, Yoshida T, Okabe M, Koike C, Fathy M, Tsuno H, Tomihara K, Arai N, Noguchi M and Nikaido T: CD44 and SSEA-4 positive cells in an oral cancer cell line HSC-4 possess cancer stem-like cell characteristics. Oral Oncol 49: 787-795, 2013.

85. Pesarrodona M, Ferrer-Miralles N, Unzueta U, Gener P, Tatkiewicz W, Abasolo I, Ratera I, Veciana J, Schwartz S Jr, Villaverde A and Vazquez E: Intracellular targeting of $\mathrm{CD} 44^{+}$cells with self-assembling, protein only nanoparticles. Int J Pharm 473: 286-295, 2014.

86. Kimura O, Takahashi T, Ishii N, Inoue Y, Ueno Y, Kogure T, Fukushima K, Shiina M, Yamagiwa Y, Kondo Y, et al: Characterization of the epithelial cell adhesion molecule $(\mathrm{EpCAM})^{+}$cell population in hepatocellular carcinoma cell lines. Cancer Sci 101: 2145-2155, 2010.

87. Zhang S, Wu CC, Fecteau JF, Cui B, Chen L, Zhang L, Wu R, Rassenti L, Lao F, Weigand S and Kipps TJ: Targeting chronic lymphocytic leukemia cells with a humanized monoclonal antibody specific for CD44. Proc Natl Acad Sci USA 110: 6127-6132, 2013.

88. Cho JH, Lee SC, Ha NR, Lee SJ and Yoon MY: A novel peptide-based recognition probe for the sensitive detection of CD44 on breast cancer stem cells. Mol Cell Probes 29: 492-499, 2015.

89. Park HY, Lee KJ, Lee SJ and Yoon MY: Screening of peptides bound to breast cancer stem cell specific surface marker CD44 by phage display. Mol Biotechnol 51: 212-220, 2012.

90. Munz M, Baeuerle PA and Gires O: The emerging role of EpCAM in cancer and stem cell signaling. Cancer Res 69: 5627-5629, 2009.

91. Yamashita T, Ji J, Budhu A, Forgues M, Yang W, Wang HY, Jia H, Ye Q, Qin LX, Wauthier E, et al: EpCAM-positive hepatocellular carcinoma cells are tumor-initiating cells with stem/progenitor cell features. Gastroenterology 136: 1012-1024, 2009.

92. Ricci-Vitiani L, Lombardi DG, Pilozzi E, Biffoni M, Todaro M, Peschle C and De Maria R: Identification and expansion of human colon-cancer-initiating cells. Nature 445: 111-115, 2007.

93. Li C, Heidt DG, Dalerba P, Burant CF, Zhang L, Adsay V, Wicha M, Clarke MF and Simeone DM: Identification of pancreatic cancer stem cells. Cancer Res 67: 1030-1037, 2007.

94. Schmelzer E and Reid LM: EpCAM expression in normal, non-pathological tissues. Front Biosci 13: 3096-3100, 2008. 
95. Terris B, Cavard C and Perret C: EpCAM, a new marker for cancer stem cells in hepatocellular carcinoma. J Hepatol 52: 280-281, 2010.

96. Cioffi M, Dorado J, Baeuerle PA and Heeschen C: EpCAM/CD3-bispecific T-cell engaging antibody MT110 eliminates primary human pancreatic cancer stem cells. Clin Cancer Res 18: 465-474, 2012.

97. Alibolandi M, Ramezani M, Sadeghi F, Abnous K and Hadizadeh F: Epithelial cell adhesion molecule aptamer conjugated PEG-PLGA nanopolymersomes for targeted delivery of doxorubicin to human breast adenocarcinoma cell line in vitro. Int J Pharm 479: 241-251, 2015.

98. Yamashita T, Forgues M, Wang W, Kim JW, Ye Q, Jia H, Budhu A, Zanetti KA, Chen Y, Qin LX, et al: EpCAM and alpha-fetoprotein expression defines novel prognostic subtypes of hepatocellular carcinoma. Cancer Res 68: 1451-1461, 2008.

99. Gires $\mathrm{O}$ and Bauerle PA: EpCAM as a target in cancer therapy. J Clin Oncol 28: e239-e242, 2010.

100. Kurtz JE and Dufour P: Adecatumumab: An anti-EpCAM monoclonal antibody, from the bench to the bedside. Expert Opin Biol Ther 10: 951-958, 2010.

101. Bae JS, Noh SJ, Jang KY, Park HS, Chung MJ, Park CK and Moon WS: Expression and role of epithelial cell adhesion molecule in dysplastic nodule and hepatocellular carcinoma. Int J Oncol 41: 2150-2158, 2012.

102. Tanimizu N, Nishikawa M, Saito H, Tsujimura T and Miyajima A: Isolation of hepatoblasts based on the expression of Dlk/Pref-1. J Cell Sci 116: 1775-1786, 2003.

103. Sununliganon L and Singhatanadgit W: Highly osteogenic PDL stem cell clones specifically express elevated levels of ICAM1, ITGB1 and TERT. Cytotechnology 64: 53-63, 2012.

104. Assis AC, Carvalho JL, Jacoby BA, Ferreira RL, Castanheira P, Diniz SO, Cardoso VN, Goes AM and Ferreira AJ: Time-dependent migration of systemically delivered bone marrow mesenchymal stem cells to the infarcted heart. Cell Transplant 19: 219-230, 2010.

105. De Francesco F, Tirino V, Desiderio V, Ferraro G, D'Andrea F, Giuliano M, Libondi G, Pirozzi G, De Rosa A and Papaccio G: Human CD34/CD90 ASCs are capable of growing as sphere clusters, producing high levels of VEGF and forming capillaries. PLoS One 4: e6537, 2009.

106. Brooke G, Tong H, Levesque JP and Atkinson K: Molecular trafficking mechanisms of multipotent mesenchymal stem cells derived from human bone marrow and placenta. Stem Cells Dev 17: 929-940, 2008.

107. Liu S, Li N, Yu X, Xiao X, Cheng K, Hu J, Wang J, Zhang D, Cheng S and Liu S: Expression of intercellular adhesion molecule 1 by hepatocellular carcinoma stem cells and circulating tumor cells. Gastroenterology 144: 1031-1041, 2013.
108. Barclay AN and Brown MH: The SIRP family of receptors and immune regulation. Nat Rev Immunol 6: 457-464, 2006.

109. Oldenborg PA, Gresham HD and Lindberg FP: CD47-signal regulatory protein alpha (SIRPalpha) regulates Fcgamma and complement receptor-mediated phagocytosis. J Exp Med 193: 855-862, 2001.

110. Okazawa H, Motegi S, Ohyama N, Ohnishi H, Tomizawa T, Kaneko Y, Oldenborg PA, Ishikawa $\mathrm{O}$ and Matozaki T: Negative regulation of phagocytosis in macrophages by the CD47-SHPS-1 system. J Immunol 174: 2004-2011, 2005.

111. Blazar BR, Lindberg FP, Ingulli E, Panoskaltsis-Mortari A, Oldenborg PA, Iizuka K, Yokoyama WM and Taylor PA: CD47 (integrin-associated protein) engagement of dendritic cell and macrophage counterreceptors is required to prevent the clearance of donor lymphohematopoietic cells. J Exp Med 194: 541-549, 2001.

112. Oldenborg PA, Zheleznyak A, Fang YF, Lagenaur CF, Gresham HD and Lindberg FP: Role of CD47 as a marker of self on red blood cells. Science 288: 2051-2054, 2000.

113. Majeti R, Chao MP, Alizadeh A A, Pang WW, Jaiswal S, Gibbs KD Jr, van Rooijen N and Weissman IL: CD47 is an adverse prognostic factor and therapeutic antibody target on human acute myeloid leukemia stem cells. Cell 138: 286-299, 2009.

114. Chao MP, Jaiswal S, Weissman-Tsukamoto R, Alizadeh AA, Gentles AJ, Volkmer J, Weiskopf K, Willingham SB, Raveh T, Park CY, et al: Calreticulin is the dominant pro-phagocytic signal on multiple human cancers and is counterbalanced by CD47. Sci Transl Med 2: 63ra94, 2010.

115. Willingham SB, Volkmer JP, Gentles AJ, Sahoo D, Dalerba P, Mitra SS, Wang J, Contreras-Trujillo H, Martin R, Cohen JD, et al: The CD47-signal regulatory protein alpha (SIRPa) interaction is a therapeutic target for human solid tumors. Proc Natl Acad Sci USA 109: 6662-6667, 2012.

116. Lee TK, Cheung VC, Lu P, Lau EY, Ma S, Tang KH, Tong M, Lo J and Ng IO: Blockade of CD47-mediated cathepsin S/protease-activated receptor 2 signaling provides a therapeutic target for hepatocellular carcinoma. Hepatology 60: 179-191, 2014.

117. Lei ZJ, Wang J, Xiao HL, Guo Y, Wang T, Li Q, Liu L, Luo X, Fan LL, Lin L, et al: Lysine-specific demethylase 1 promotes the stemness and chemoresistance of $\mathrm{Lgr}^{+}$liver cancer initiating cells by suppressing negative regulators of $\beta$-catenin signaling. Oncogene 34: 3214, 2015. 